\title{
A Study on designing appropriate hydraulic fracturing treatment with proper material selection and optimized fracture half-length in tight multilayered formation sequence
}

\author{
Temoor Muther $^{1}$ (D) Muhammad Jawad Khan² $\cdot$ Muhammad Hanif Chachar ${ }^{3} \cdot$ Hassan Aziz $^{4}$
}

Received: 11 January 2020 / Accepted: 8 April 2020 / Published online: 11 April 2020

(c) Springer Nature Switzerland AG 2020

\begin{abstract}
Hydraulic fracturing is widely accepted technology to unlock unconventional reservoirs and produce the hydrocarbon fluids at feasible rates, but reaching these rates requires an optimal designing of the hydraulic fracturing treatment. This study presents an approach to design an appropriate hydraulic fracture with proper material selection and optimized fracture half-lengths. In this approach, initially, a hydraulic fracture model is selected for fracture design while considering formation stresses and fracture propagation. After that, the proppants and fracturing fluids are selected based on in-situ stresses, hydraulic fracture permeability and conductivity, the sensitivity of formation with water, pressure and temperature conditions of the reservoir. After the selection of the above materials, five hydraulic fractures with fracture half-lengths of $318 \mathrm{ft}, 415 \mathrm{ft}, 539 \mathrm{ft}, 618 \mathrm{ft}$, and $724 \mathrm{ft}$ are selected based on the amounts of proppants pumped, and their production responses are plotted. After comparing the selected fractures, the optimal fracture treatment is achieved at fracture half-length of $618 \mathrm{ft}$ due to its high fluid recovery, along with the low amount of proppant pumped (127 klbs), which ultimately increases revenue and puts less burden on the economics of the project. The approach used in this study will, therefore, help design future hydraulic fracture treatment with an optimized hydraulic fracture, resulting in high hydrocarbon production rates, and reduce the overall cost by selecting the compatible fracturing fluids and adequate amounts of proppants.
\end{abstract}

Keywords Hydraulic fracture design · Proppants · Fracturing fluids - Unconventional reservoirs - Tight gas productivity . Hydraulic fracturing $\cdot$ Multi-layered formations

\begin{tabular}{|c|c|c|c|}
\hline \multicolumn{2}{|c|}{ List of symbols } & \multirow[t]{2}{*}{ Lf } & \multirow{2}{*}{$\begin{array}{l}\text { Fracture length (conductive and of single } \\
\text { wing) }\end{array}$} \\
\hline md & Milli darcy & & \\
\hline MMSCF & Million standard cubic feet & FOI & Fold of increase \\
\hline MMSCFD & Million standard cubic feet per day & $\mathrm{PI}$ & Productivity index \\
\hline $\mathrm{cp}$ & Centi poise & Gal & Gallons \\
\hline Fcd & Dimensionless fracture conductivity & Ppg & Pounds per gallon \\
\hline kf & Fracture permeability & Bpm & Barrels per minute \\
\hline w & Fracture width & Klbs & Kilo pounds \\
\hline & Formation permeability & & \\
\hline
\end{tabular}

$\triangle$ Temoor Muther, temoormuther@ymail.com; temoormuther@muetkhp.edu.pk| ${ }^{1}$ Department of Petroleum and Natural Gas Engineering, Mehran UET, SZAB Campus, Khairpur Mirs, Sindh, Pakistan. ${ }^{2}$ Department of Petroleum and Gas Engineering, NFC IET, Multan, Pakistan. ${ }^{3}$ Institute of Petroleum and Natural Gas Engineering, Mehran UET, Jamshoro, Pakistan. ${ }^{4}$ Department of Petroleum and Gas Engineering, Dawood UET, Karachi, Pakistan. 


\section{Introduction}

Hydraulic fracturing is a major well-stimulation technology widely used to recover unconventional reservoirs [4]. One of the major types of those reservoirs is tight gas reservoirs. Tight gas reservoirs contain natural gas sealed in extremely impermeable tight formation [1]. They have a matrix permeability of less than $0.1 \mathrm{md}\left(1 \times 10^{-16} \mathrm{~m}^{2}\right)$ and a matrix porosity of about 10 percent [2]. Moreover, they are characterized by low porosity and permeability, low productivity, and a small drainage radius. Consequently, a hydraulic fracturing treatment is always required to produce such reservoirs at economically feasible rates [4].

Hydraulic fracturing operation involves the creation of fractures into the formation through a fracturing fluid or frac fluid. This fluid is injected, at a specified pressure and flow rate, to create and extend the fracture deep into the formation. During hydraulic fracturing operation, a "pad fluid" is generally injected first to initiate the fracture. Later, a fracturing fluid containing proppants is injected at an adequate flow rate and pressure to extend the created fracture deep into the formation. The purpose of using these proppants is to create a proppant-filled (propped) region from the fracture tip to the wellbore. This region keeps the fracture open and allows a high permeable path for the hydrocarbon fluids to flow from the reservoir to the wellbore [1]. As a result, the hydrocarbon gas produces at higher rates as compared to rates obtained earlier before hydraulic fracturing operation.

Since hydraulic fracturing is required in tight gas reservoirs, to produce at economical rates, therefore, an optimized hydraulic fracturing treatment is always needed. This optimized treatment depends upon many factors. It includes the selection of appropriate materials for the effective creation of hydraulic fractures, prediction of various hydraulic fracture lengths for high productivity from the formation and conductivities of hydraulic fractures [3].

In this study, an approach has been established to design hydraulic fracturing treatment in a tight gas reservoir. This approach will be helpful in designing future hydraulic fracture treatment with an optimized hydraulic fracture, resulting in high hydrocarbon production rates, and reducing the overall cost by selecting the compatible fracturing fluids and adequate amounts of proppants. This approach uses the following steps: (1) Selecting a hydraulic fracture model based on formation stresses, fracture propagation, and confining mechanisms. (2) Selecting an appropriate proppant based on in-situ stresses and high proppant permeability. (3)
Selection of fracturing fluids based on the sensitivity of water with formation, the viscosity of the fracturing fluid, pressure and temperature condition of the reservoir. (4) Simulating hydraulic fracture half-lengths based on the selected materials. (5) Comparing those fracture halflengths to determine an optimum fracture half-length and hence an optimum hydraulic fracture treatment. The workflow of this approach is shown in Fig. 1.

In this study, the reservoir considered for hydraulic fracturing treatment is a sandstone reservoir drilled with a vertical well. The total depth TD of the well is 11,355.4 $\mathrm{ft}$. The formation consists of a shale-sand-shale sequence. The payzone is sandstone with an average permeability of $0.154 \mathrm{mD}$, a pressure of about $4847 \mathrm{psi}$ and a temperature of $335^{\circ} \mathrm{F}$. Moreover, the reservoir consists of a gas with appreciable amount of water. Further, the well without fracture was initially flowing at 0.92 MMSCFD [5].

\section{Selection of model}

The hydraulic model selection is a critical phase while designing any hydraulic fracturing treatment. It has been found through the monitoring of actual field treatments that fracture grows in a complicated manner because of layering, heterogeneity, and natural fractures in the formation [6]. Therefore, selecting a fracturing model is highly dependant upon the formation characteristics.

The hydraulic fracture models are categorized into twodimensional models, pseudo-three-dimensional (P3D) models and three-dimensional models (see Fig. 2) [6-8]. In two-dimensional models, 2D analytical equations are used in which the height of the fracture is assumed [9]. The Perkins-Kern-Nordgren (PKN) and Khristianovic-Geertsma-de Klerk (KGD) are the two most common models used for $2 \mathrm{D}$ fracture treatment design with former is used when the fracture half-length is sufficiently large enough than fracture width whereas the later is used with higher fracture

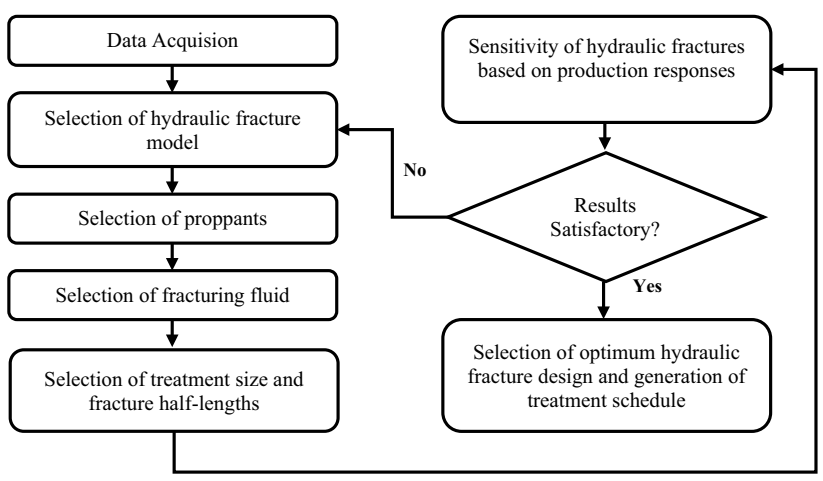

Fig. 1 Hydraulic fracture design approach 


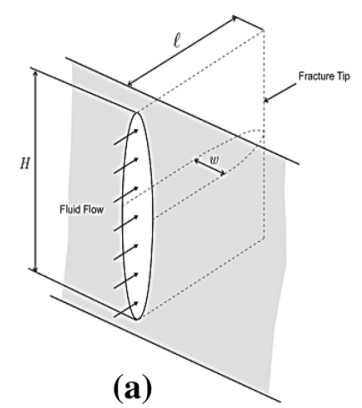

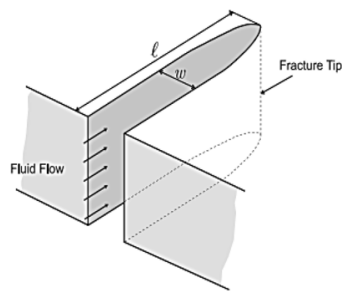

(b)

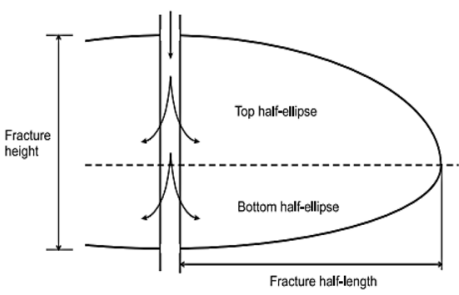

(c)

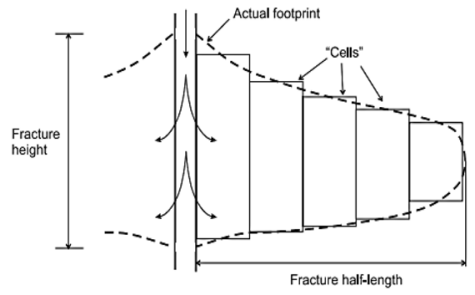

(d)

Fig. 2 Different hydraulic fracture models: a PKN Geometry, b KGD Geometry, c P3D lumped model, d P3D cell-based model [6]

heights than fracture lengths [10]. These models, however, cannot be applied for layered reservoirs and are not able to simulate both lateral and vertical propagation [7].

The pseudo-three-dimensional models counter the above disadvantages of analytical models and are first introduced for modeling fractures in multi-layered reservoirs [7]. These models are characterized into lumped (or elliptical) and cell-based models. In lumped models, there are two half-ellipses in the fracture shape that are connected at the center. In these models, the fracture shape assumed is matched with the calculated horizontal length and vertical tip extensions. This model assumes that the fluid flow is along the predetermined streamlines from perforated interval to the edges of the fracture. In cellbased models, the shape of the fracture is not defined. The fracture is discretized in small PKN-like cells with different heights and fluid flow is generally approximated. The pressure in the cell helps to calculate the height at any cross-section [6-8].

In three-dimensional models, the propagation of fracture is in all dimensions with non-ideal geometry and growth regime. They are either planar 3D models or fully $3 \mathrm{D}$ models. Such models require high computational requirements but predict accurate fracture design $[7,8]$.

The growth of hydraulic fractures varies depending on the formation being stimulated. In a tight formation, it has been found through various micro-seismic hydraulic fracture mappings that the hydraulic fractures are more confined than they should be through the conventional confining mechanisms such as stress barriers and permeability facies [11]. This phenomenon is known as composite layering effect (CLE). This phenomenon explains why it is easier for a fracture to propagate along layer boundaries (hydraulic fracture length) than to grow across layer interfaces (hydraulic fracture height) [12]. Figure 3 shows composite layering effect.

Since the reservoir considered in this study is a tight sandstone reservoir with a shale-sand-shale layer sequence, therefore, the confinement of fracture in the formation is expected. Therefore, considering the insitu

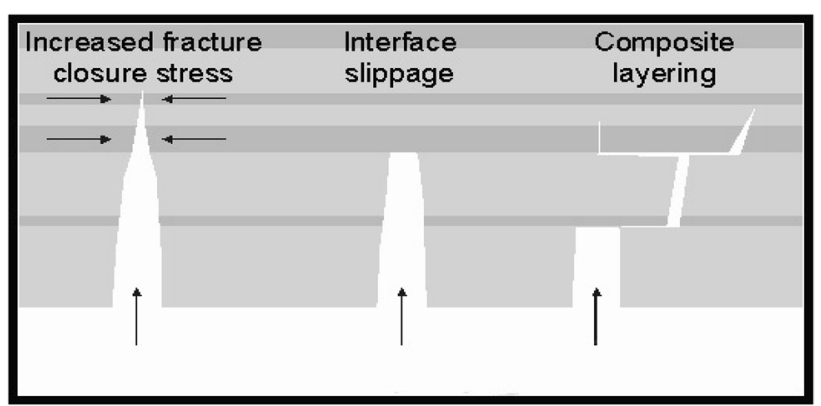

Fig. 3 Composite layer effect [12]

response of the formation and sensitivity of hydraulic fracture to confining stresses, the 3D shear-decoupled model, provided by the commercial simulator, has been used in this study for designing hydraulic fracturing treatment. This model predicts a more confined and longer hydraulic fracture caused by composite layering. Moreover, this model widely describes CLE in tight gas sands as the tight gas sands are supposed to exhibit this behavior. Such confinement and variable fracture growth cannot be accurately determined through $2 \mathrm{D}$ analytical models as they either may under-estimate or over-estimate the fracture geometry values in the formation.

\section{Selection of proppant}

The proper selection of proppant is necessary for any optimized hydraulic fracture as they keep it open and allow conducive flow through it. The primary consideration for selecting any proppant must be given to its behavior under stress conditions, along with its permeability and conductivity [9]. Higher proppant permeability and conductivity results in higher production from the reservoir. Economides and Nolte [13] developed a chart for understanding the effect of stress on proppant permeability as shown in Fig. 4. Another critical factor that needs consideration is the proppant Beta factor. It is also termed as 


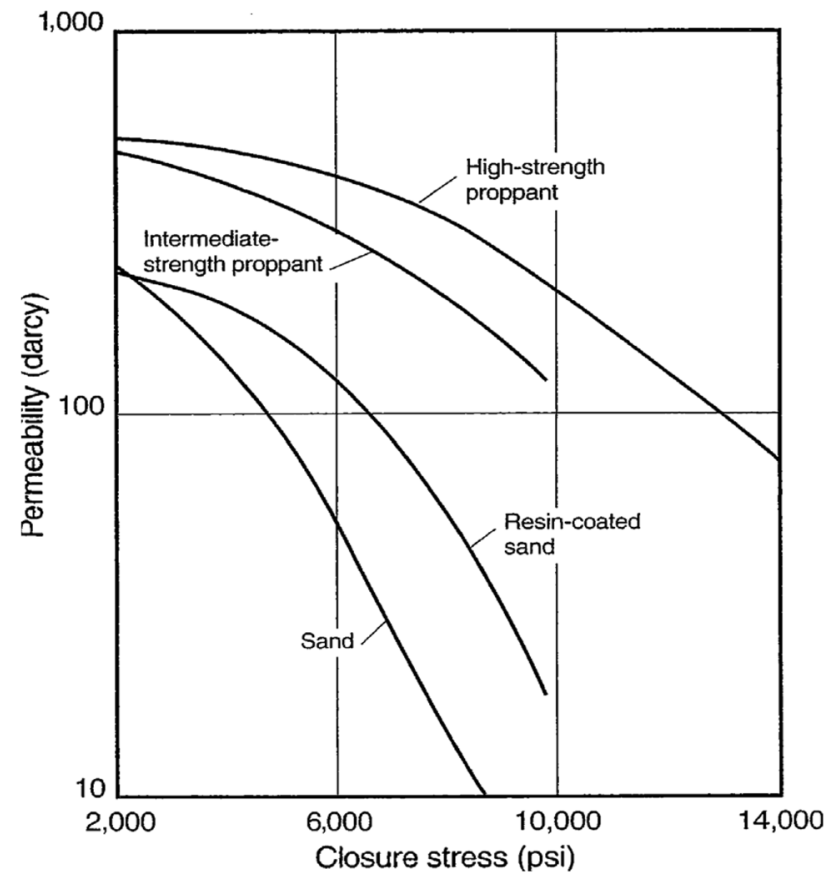

Fig. 4 Effect of fracture closure stress on proppant pack permeability [13]

non-Darcy flow coefficient or inertial flow coefficient. The beta factor deals with the non-Darcy pressure drop effects in the fracture. A significantly lower value of the beta factor reduces non-Darcy pressure drops in the fracture [16]. This leads to improved conductivity resulting in increased flow rate and high recovery of hydrocarbons.

As the closure stress plays its part in the selection of proppant and the closure stress of considered sandstone rock is 6871 psi, therefore, based on the Economides and Nolte chart, resin-coated proppants are selected for the study. These proppants are available at different mesh sizes. Hence, the selection of mesh size is very critical for easy admittance of proppants into the pores. The perforation diameter of the well in the current scenario is 0.32 inches, so the proppant size must be 8 to 10 times smaller than the perforation diameter for easy admittance. Therefore, the proppants with 20/40 mesh sizes have been shortlisted.

In order to determine the optimal 20/40 proppants, sensitivity has been carried in the simulator on the following proppants for proppant permeability, proppant conductivity, and proppant beta factor. The values of these properties are determined on the effective stress on proppant. The effective stress is simulated to be 3371 psi.

- Atlas PRC Premium 20/40.

- MagnaProp 20/40.

- CarboProp 20/40.

SN Applied Sciences
- Ceramax | 20/40.

Out of these four proppants, CarboProp 20/40 has been selected for fracturing treatment as an optimal proppant because of higher permeability, higher conductivity and lower Beta-factor under stress. Figures 5, 6,7 shows the permeability, conductivity and Beta factor for each shortlisted proppant under stress of sandstone formation.

\section{Proppant Permeability}

$\square$ Atlas PRC Premium 20/40 $\square$ MagnaProp 20/40

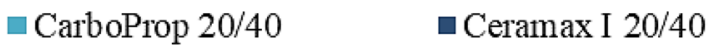

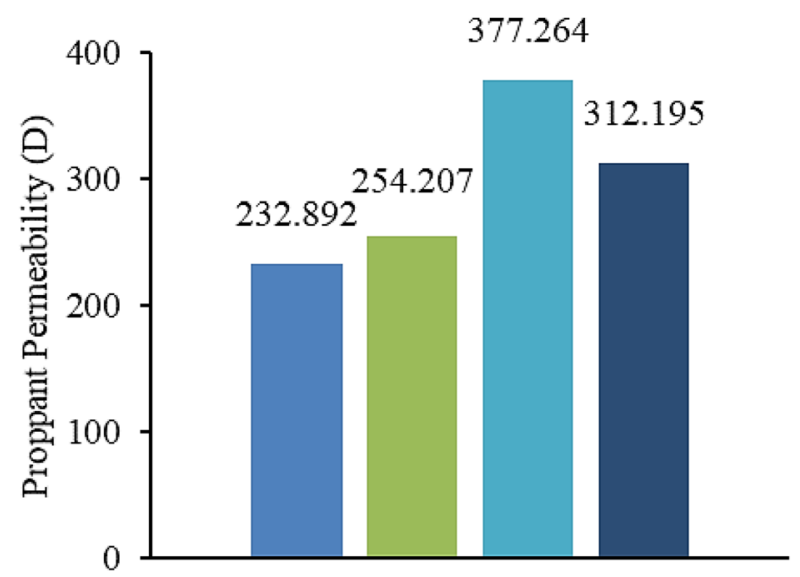

Fig. 5 Proppant permeability under effective stress

\section{Proppant conductivity}

$\square$ Atlas PRC Premium 20/40 $\square$ MagnaProp 20/40

$\square$ CarboProp 20/40 $\quad$ Ceramax I 20/40

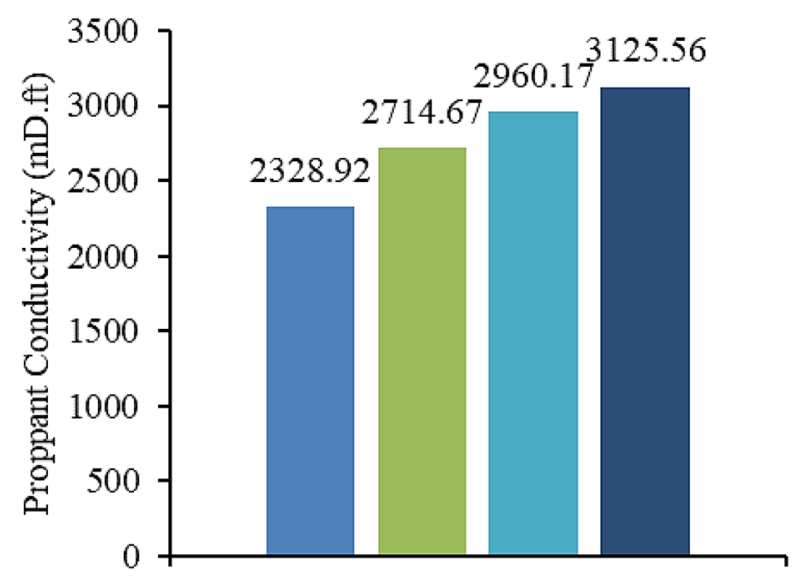

Fig. 6 Proppant conductivity under effective stress 


\section{Proppant Beta Factor}

$\begin{array}{ll}\square \text { Atlas PRC Premium 20/40 } & \square \text { MagnaProp 20/40 } \\ \square \text { CarboProp 20/40 } & \square \text { Ceramax I 20/40 }\end{array}$

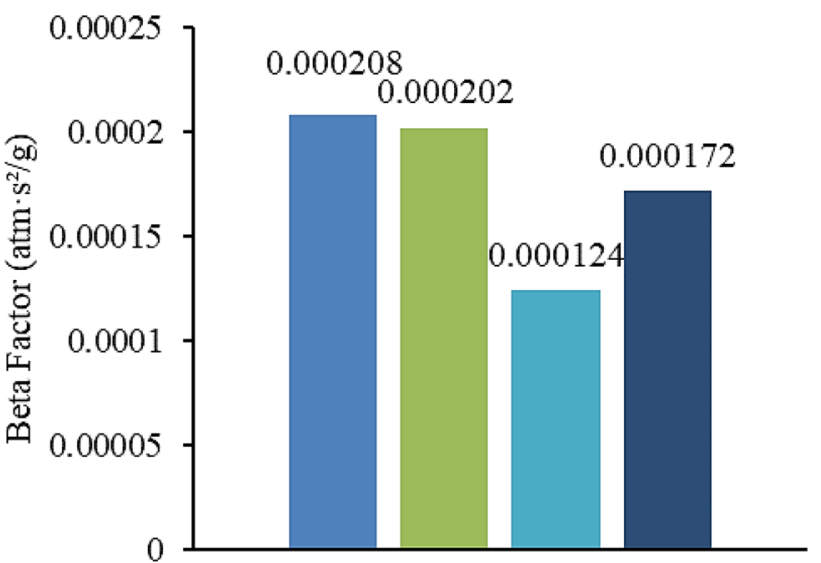

Fig. 7 Proppant Beta factor under stress

\section{Fracturing fluid selection}

Fluid selection is an important part in designing a hydraulic fracture. In this study, the fracturing fluid selection is based on compatibility with the reservoir formation and viscosity of the fluid. Economides et al. [14] fluid selection chart largely helps in selection of optimum fracturing fluid for fracturing treatment. The fluid selection chart based on Economides et al. study, in a gas well is shown in Fig. 8. For viscosity of the fluid, the criteria used in this study is to obtain atleast 200 $\mathrm{cp}$ apparent viscosity at $401 / \mathrm{s}$ after $1 \mathrm{~h}$ of exposure to reservoir temperature [12].

Considering the above criteria, as the reservoir is a highpressure gas reservoir with temperature around $335^{\circ} \mathrm{F}$, the water-based zirconate-crosslinked CMHPG (Carboxymethyl hydroxypropyl guar) fluid is selected as optimum for the study. Following two CMHPG-Zircon fluids are available in the industry for high temperature environment.

- YF800HT

- PrimeFRAC.

Both the fluids fall under the viscosity criteria described earlier. Hence, any of these fluids can be used for optimum design. A $2 \%$ addition of $\mathrm{KCl}$ in this water-based fluid can prevent clay swelling. In this study, PrimeFRAC has been used for fracturing treatment.

\section{Selection of treatment size}

For the selection of a particular treatment size, the dimensionless fracture conductivity is critical. According to a correlation given by Cinco-Ley and Samaniego [15], the increase in dimensionless fracture conductivity (FcD) upto 15 results in the increase in effective wellbore radius however after 15 there will be no increase in the effective wellbore radius and hence no effect on the performance of well [15]. This correlation is shown in Fig. 9. Therefore, for designing hydraulic fracture in this study, the FCD goal in the simulator is set between 10 and 15 so that the hydraulic fracture design is simulated within this range of $\mathrm{FCD}$. Moreover, the maximum amount of production can be obtained through the designed hydraulic fracture.

Fig. 8 Fluid selection chart [14]

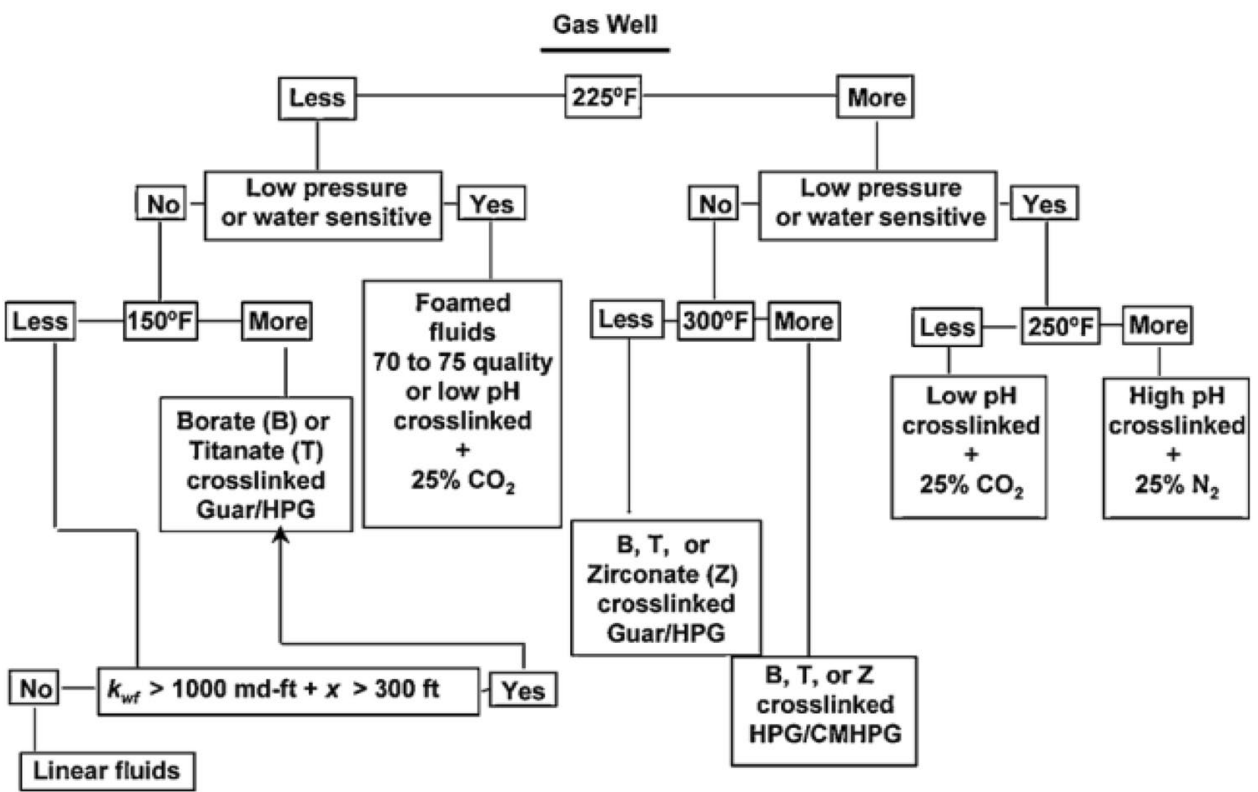


Fig. 9 Correlation between dimensionless fracture conductivity and effective wellbore radius [15]

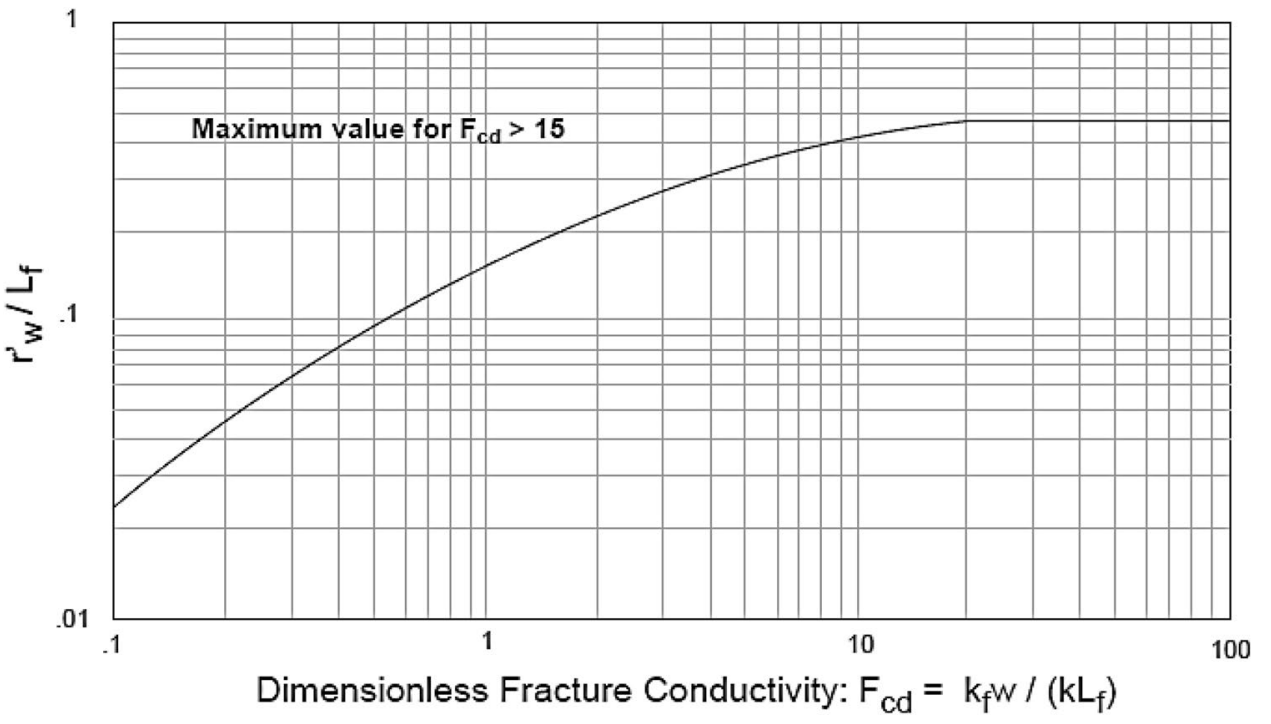

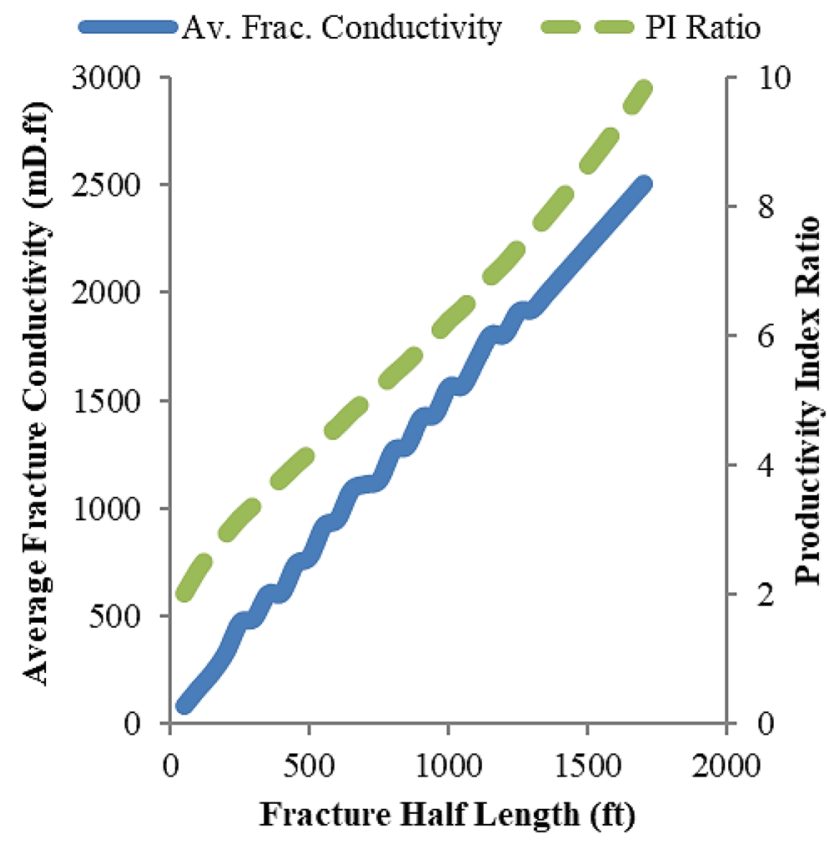

Fig. 10 Average fracture conductivity and productivity index ratio versus Fracture half-length

Apart from FcD, it has also been found that the fracture lengths greatly benefit the production in a low permeable reservoir [8]. Hence, while setting dimensionless conductivity values prior attention must also be given to fracture lengths. A simulated relationship between fracture half-length and fracture conductivity is shown in Fig. 10 . The relationship is found to be linear and shows that high fracture conductivities can be obtained with high fracture half-lengths. Another relationship between fracture half-length and productivity index ratio is also plotted in Fig. 10. It shows a linear increase in productive index while

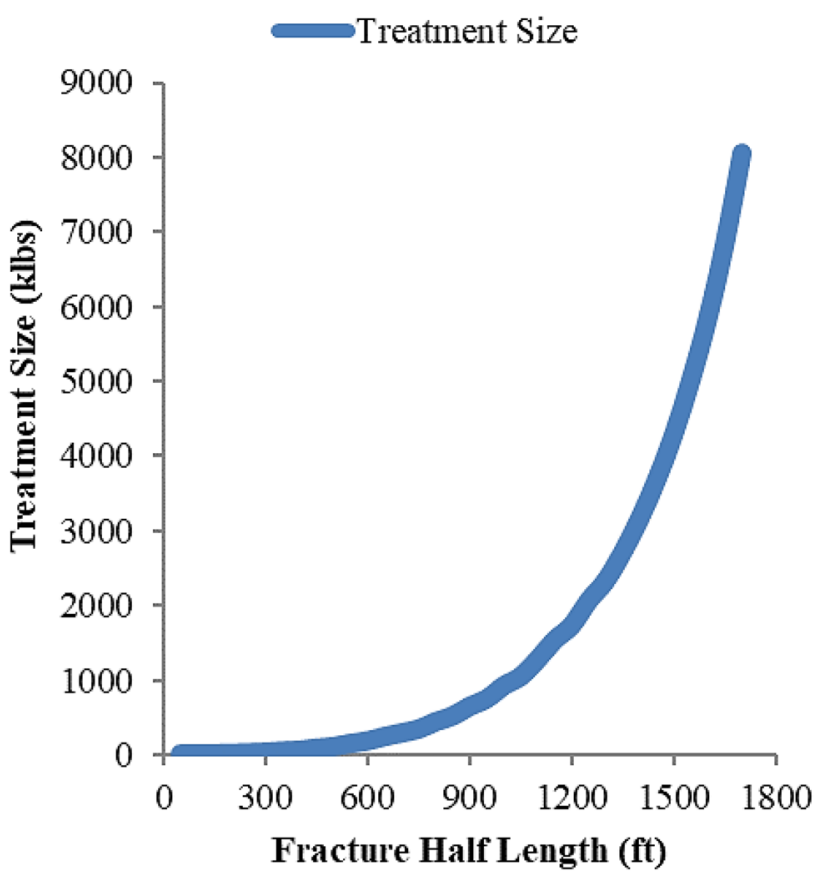

Fig. 11 Treatment size versus Fracture Half-length

increasing the fracture half-length. This quantifies that high production can be achieved with high productivity index. Another important relationship between fracture half-length and treatment size (total proppant pumped) is also plotted in Fig. 11 which can greatly help in selecting an optimum fracture half-length in a given treatment.

The figure shows that with the increase in treatment size, the fracture half-length is increasing. From 0 to $800 \mathrm{ft}$, it can be seen that the fracture half-length has increased considerably with a slight increase in the treatment size. However, after $800 \mathrm{ft}$, a large increase in treatment size 
results in a slight increase in fracture half-lengths. As higher the treatment size, the higher the cost will be for the fracturing design. Hence, the optimum fracture design can be achieved with the fracture half-lengths of less than $800 \mathrm{ft}$.

\section{Results and discussion}

Based on the above considerations, five simulated fractures are obtained having different fracture half-lengths and other treatment parameters. The simulated fractures alongwith its different properties are shown in Table 1.

These simulation results show that larger fracture halflength requires the pumping of a high amount of proppants. For $318 \mathrm{ft}$, a total of $16.7 \mathrm{klbs}$ of proppant is required by fracture, whereas, for $724 \mathrm{ft}$, an amount of $200 \mathrm{klbs}$ is needed. This increase in the pumping of proppants is desirable because high fracture half-length requires more proppants to cover the fracture volume and develop a propped zone. This zone will be capable of transmitting a high volume of gas from the reservoir to the fracture and from fracture to the wellbore.

With the increase in proppants, the propped fracture half-length is increasing from $247 \mathrm{ft}$ in fracture half-length of $318 \mathrm{ft}$ to $675 \mathrm{ft}$ in fracture half-length of $724 \mathrm{ft}$. With this, the propped height has significantly increased from 83 to $192 \mathrm{ft}$. Also, the fracture width has increased from 0.26 inches to 0.34 inches. This shows that the earlier selected 3D model quantifies all three dimensions of fracture based on reservoir characteristics, fluid injection, and proppant amount.

The effect of increased proppant volume is also evident in average fracture conductivity. It causes the average fracture conductivity to increase from $614 \mathrm{mD}$.ft in 318 $\mathrm{ft}$ of fracture to $1818 \mathrm{mD}$.ft in $724 \mathrm{ft}$. With the increase in fracture conductivity, the fracture permeability will also increase. This result translates to the increase in the production of hydrocarbon gas with the increasing fracture half-lengths.

\subsection{Production performance results}

In order to understand the recovery obtained from the above specified hydraulic fractures, the production performance responses are simulated. The production constraints are set in the simulator with a maximum production rate of 9 MMSCFD and a minimum reservoir pressure limit of 500 psi. The maximum drawdown is set to 2000 psi. The production from the reservoir is forecasted for 10 years. Based on these constraints, the production performance of the reservoir is reported and plotted. The response of gas production rates w.r.t time is plotted in Fig. 12. Moreover, the cumulative gas production response w.r.t time is plotted in Fig. 13. The reservoir pressure depletion profile and productivity index as a function of time is also plotted in Figs. 14 and 15 respectively.

As per the production rate graph (see Fig. 12), the well without fracture is flowing at 0.9 MMSCFD. After applying the fracturing treatment, gas production rates have increased. At $318 \mathrm{ft}$ fracture, the gas production rates are between 4 and 2 MMSCFD. With the increase in fracture

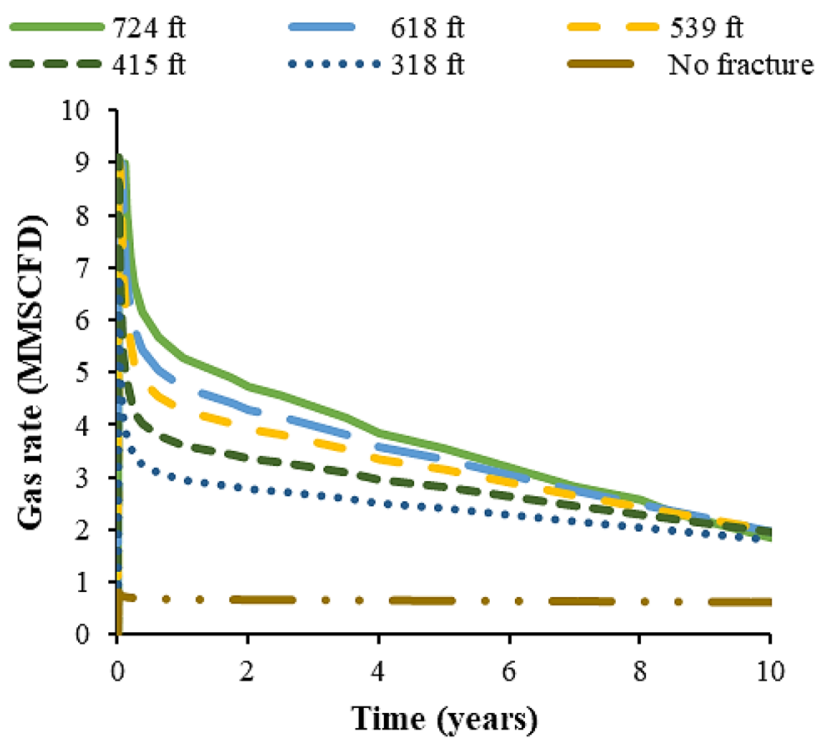

Fig. 12 Gas rate versus time

Table 1 Designed fractures

\begin{tabular}{llllllll}
\hline $\begin{array}{l}\text { Fracture half- } \\
\text { length (ft) }\end{array}$ & $\begin{array}{l}\text { Propped half- } \\
\text { length (ft) }\end{array}$ & $\begin{array}{l}\text { Dimensionless } \\
\text { conductivity }\end{array}$ & $\begin{array}{l}\text { Average conduc- } \\
\text { tivity (mD.ft) }\end{array}$ & $\begin{array}{l}\text { Fracture } \\
\text { height (ft) }\end{array}$ & $\begin{array}{l}\text { Propped } \\
\text { height (ft) }\end{array}$ & $\begin{array}{l}\text { Fracture } \\
\text { width (in) }\end{array}$ & $\begin{array}{l}\text { Total proppant } \\
\text { pumped (klbs) }\end{array}$ \\
\hline 318 & 247 & 16.152 & 614 & 108 & 83 & 0.26 & 16.7 \\
415 & 354 & 16.63 & 906 & 126 & 107 & 0.28 & 38.5 \\
539 & 483 & 16.94 & 1259.6 & 156 & 140 & 0.3 & 80 \\
618 & 565 & 17.7 & 1541.6 & 177 & 162 & 0.32 & 127 \\
724 & 675 & 17.5 & 1818 & 206 & 192 & 0.34 & 200 \\
\hline
\end{tabular}




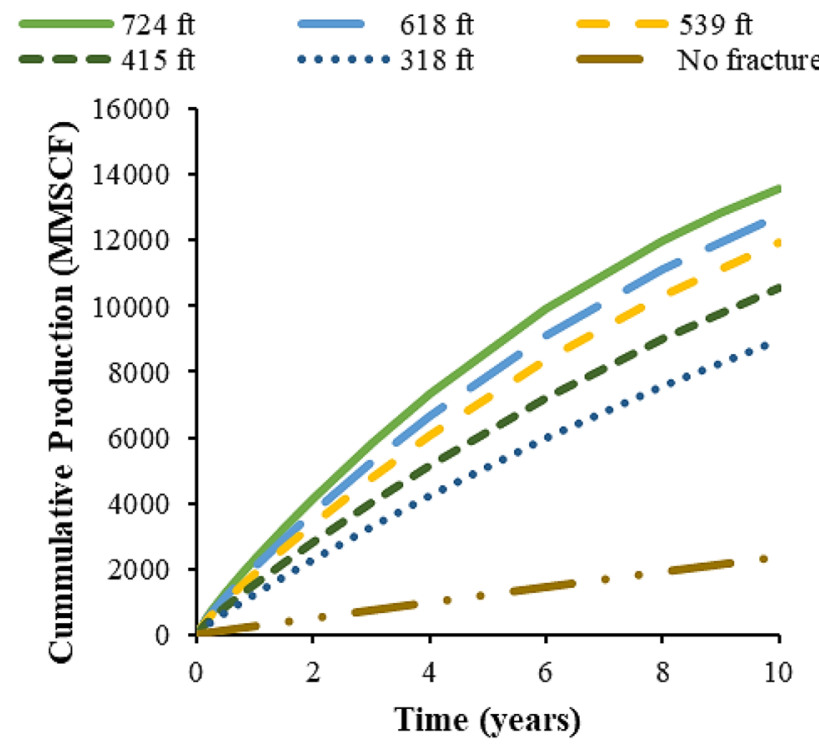

Fig. 13 Cumulative production versus time

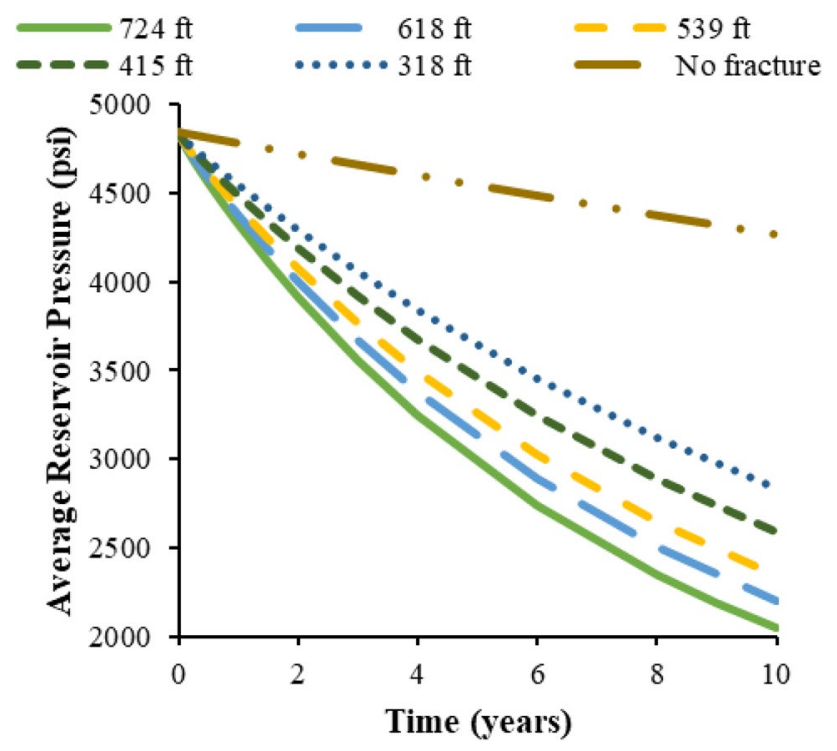

Fig. 14 Reservoir pressure depletion versus time

half-lengths (along with other simulated fracture properties), the gas production rates are increasing. The highest gas production rate is obtained at $724 \mathrm{ft}$ fracture with the initial flow of 9 MMSCFD for some time. Later, it declines to approximately 2 MMSCFD at the end of 10 years.

Since the production rates are increasing with the increasing fracture half-lengths, the cumulative production is also increasing (see Fig. 13). The simulation results show that the production obtained without hydraulic fracture is 2395 MMSCF. After hydraulic fracturing treatment, the cumulative production increases with the increase in

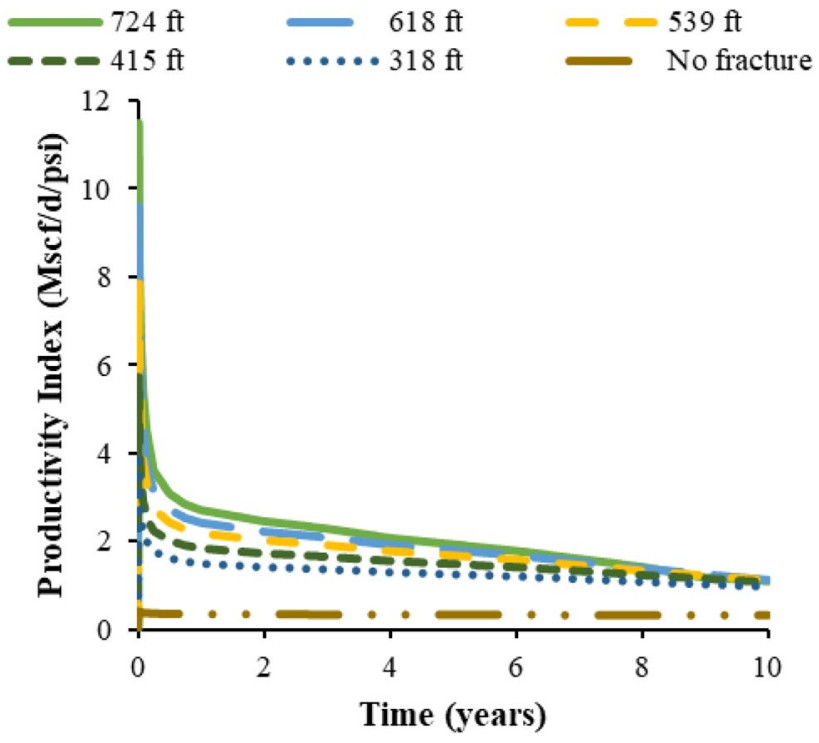

Fig. 15 Productivity index versus time

fracture half-lengths. For hydraulic fractures of $318 \mathrm{ft}, 415$ $\mathrm{ft}, 539 \mathrm{ft}, 618 \mathrm{ft}$, and $724 \mathrm{ft}$, the cumulative productions are 8990 MMSCF, 10,568 MMSCF, 11,932 MMSCF, 12,732 MMSCF and 13,595 MMSCF respectively.

The response of pressure depletion (see Fig. 14) shows that the pressure depletes to $4266 \mathrm{psi}$ at the end of 10 years when there is no fracture in the reservoir. However, after fracturing, the pressure depletes to 2840 psi, 2593 psi, 2348 psi, 2206 psi, and 2049 psi with the fracture half-lengths of $318 \mathrm{ft}, 415 \mathrm{ft}, 539 \mathrm{ft}, 618 \mathrm{ft}$, and $724 \mathrm{ft}$ respectively. Apart from this, the productivity index (see Fig. 15) varies for different conditions. Without fracturing, the productivity index is $0.32 \mathrm{Mscf} / \mathrm{d} / \mathrm{psi}$ at the end of 10 years. However, the productivity index at different fracture half-lengths varies with time, with the maximum productivity index at $724 \mathrm{ft}$ of fracture. Initially, the productivity index at that condition is around $11 \mathrm{Mscf} / \mathrm{d} /$ psi, which is later dropped to $1.1 \mathrm{Mscf} / \mathrm{d} / \mathrm{psi}$ at the end of 10 years.

\subsection{Discussion on production performance}

The above production rates and cumulative production responses show that the tight gas reservoir will perform better with the hydraulic fracturing treatment. The production responses obtained without the fracture is low as compared to the production obtained after fracturing. Moreover, the production rates and cumulative production increases with the increase in fracture half-length and the parameters responsible for it. There are various reasons for this increase in production. The production is highly dependant on the reservoir contact with the fracture. 
The higher the fracture half-length, the higher will be the contact, which results in higher production. Apart from this, the propped region also affects reservoir production. As the fracture half-length increases, the propped region increases resulting in increased reservoir production.

With the production rates and cumulative responses, the productivity index is also higher for high fracture halflength values. However, with time the productivity index tends to decrease owing to the low production rates at different values of reservoir pressure and drawdown calculated over time. Moreover, gas production is also affected by water production. As the reservoir has moderate water saturation, therefore, the water production is restricting gas production. However, its effect is not as high compared to high water saturation in the reservoir. This impact is shown in Fig. 16.

The pressure depletion profile shows that the pressure depletes largely with high fracture half-lengths. Pressure depletion is usually associated with the production of reservoirs. High reservoir pressure depletion suggests an increase in reservoir production. Since the production is significantly increasing with high fracture half-lengths, therefore, the reservoir pressure will deplete more at higher lengths.

During the production of gas from this reservoir, a significant fluid flow behavior is observed from the production rate plot. The production rate declines at a rapid pace during the early production period (see Fig. 12), however, at later stages, the production rates get stabilized. This rapid decline is due to the transient flow at the early production period in the tight gas reservoir. With time, the reservoir tends to flow at more stabilized rates reaching pseudo steady-state flow.

\subsection{Discussion on optimized fracture selection}

The criteria used for the selection of final optimized fracture and fracturing treatment is based on the production responses. As higher fracture half-lengths result in high productivity (see Figs. 12, 13, 14, 15), therefore higher fracture half-lengths greater than $500 \mathrm{ft}$ are preferred in this study. Furthermore, these higher half-lengths can be achieved with a little increment in the treatment size (Refer Fig. 11), which is also an advantage from the economics point of view.

From those higher fracture half-lengths, the fracture with a half-length of $618 \mathrm{ft}$ is considered as an optimized hydraulic fracture. Although, the $724 \mathrm{ft}$ fracture provides the highest recovery, yet, it is not considered as optimum because (1) The production rate and cumulative production of $624 \mathrm{ft}$ fracture have a lesser difference compared to $724 \mathrm{ft}$ fracture (2) $724 \mathrm{ft}$ fracture needs about $200 \mathrm{klbs}$ of proppants to be pumped, whereas, the $618 \mathrm{ft}$ fracture requires only $127 \mathrm{klbs}$, hence the additional treatment cost is not justified (3) Very high fracture half-length may get more confined from their extended tip due to insitu stresses. The fracture profile of optimized fracture alongwith the proppant concentration is shown in Fig. 17.

\subsection{Treatment schedule of selected fracture}

Inorder to achieve that optimized fracture half-length, a proper treatment schedule is needed. Table 2 shows the schedule of obtaining required fracture half-length. The whole treatment will take about $72 \mathrm{~min}$ to complete. Table 3 shows the hydraulic fracture growth of the entire fracture system and at the end of each stage.

\subsection{Discussion on approach used for optimized fracture}

As described in this study, the significant parameters required for the development of an optimized fracture includes the appropriate selection of proppants, fracturing fluids, predictive fracture model, and treatment sizes. It is necessary to quantify all these parameters accurately
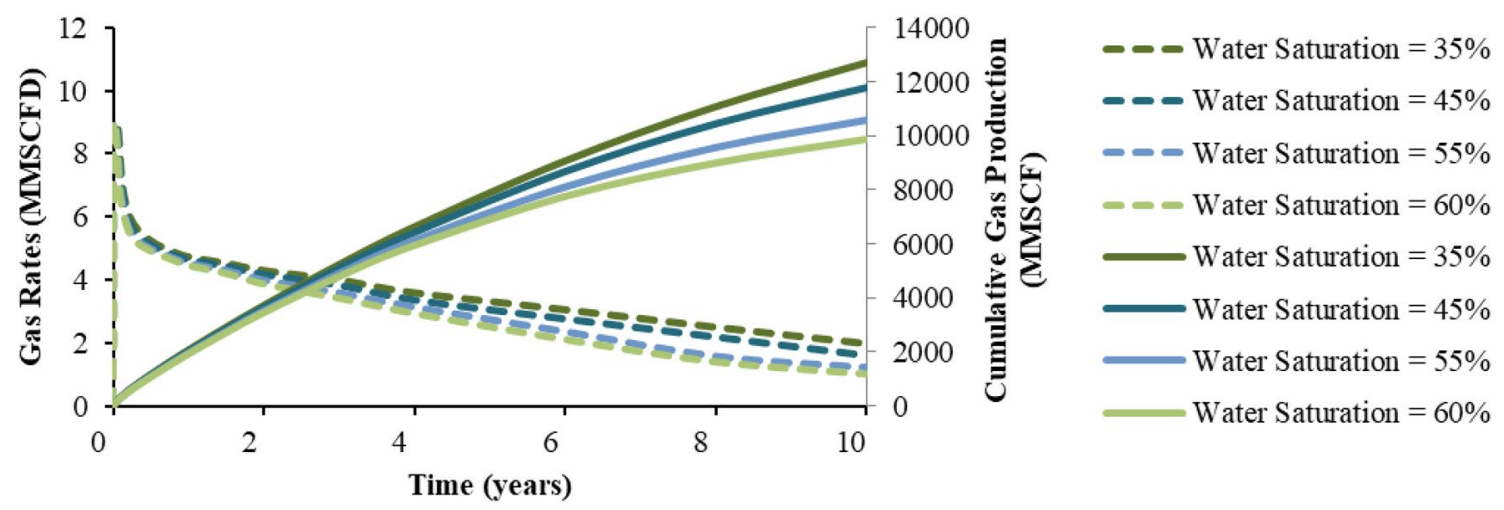

Fig. 16 Gas production response of $618 \mathrm{ft}$ fracture as a function of water saturation 


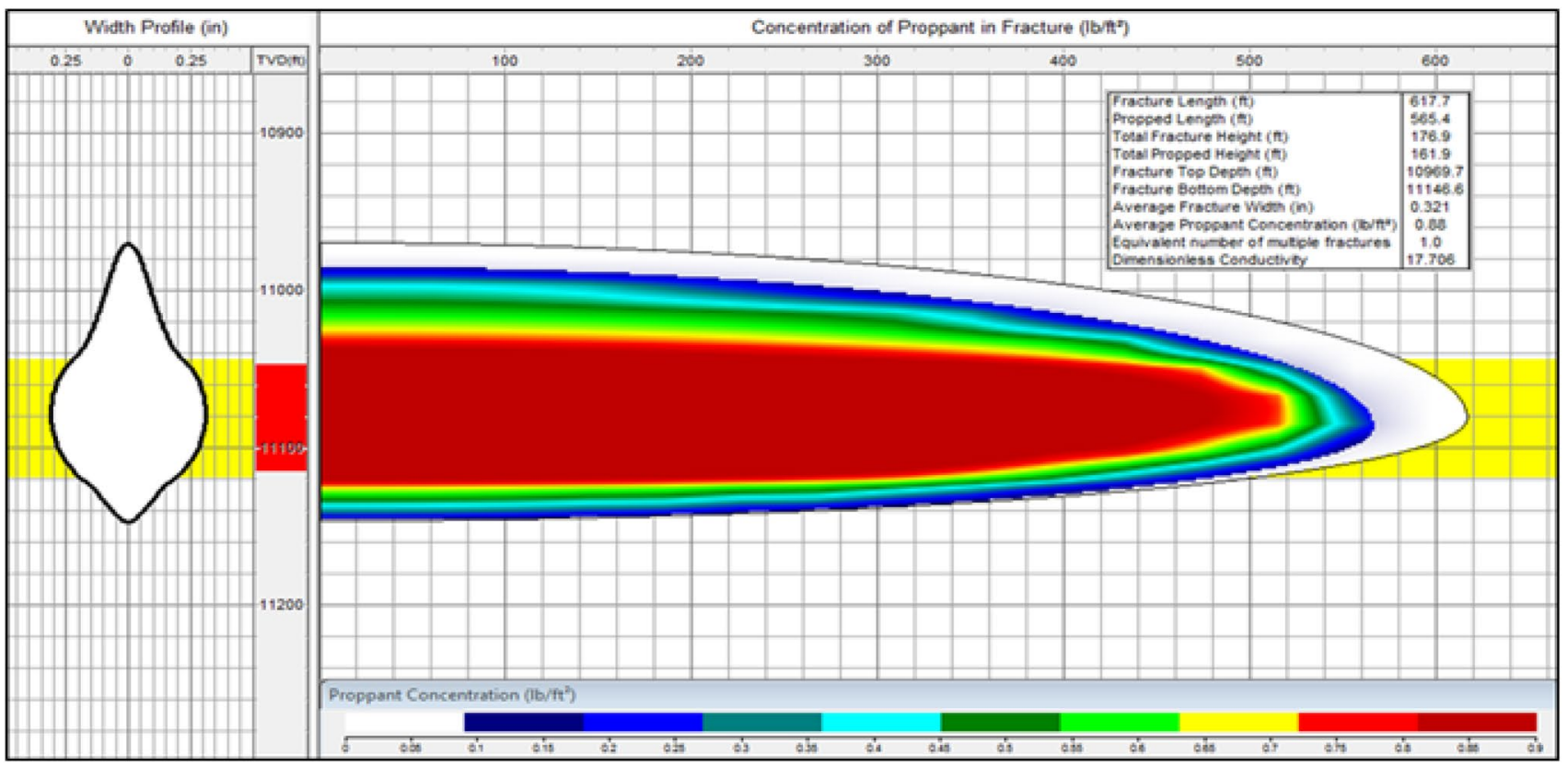

Fig. 17 Concentration of proppant and width profile

Table 2 Treatment schedule

\begin{tabular}{|c|c|c|c|c|c|c|c|c|}
\hline Stage \# & Stage type & $\begin{array}{l}\text { Elapsed } \\
\text { Time } \\
\text { min:s }\end{array}$ & Fluid type & $\begin{array}{l}\text { Clean } \\
\text { volume } \\
\text { (gal) }\end{array}$ & $\begin{array}{l}\text { Prop } \\
\text { conc. } \\
\text { (ppg) }\end{array}$ & $\begin{array}{l}\text { Stage } \\
\text { prop. } \\
\text { (klbs) }\end{array}$ & Slurry rate (bpm) & Proppant type \\
\hline 1 & Pad & $8: 55$ & PrimeFRAC 15 & 6000 & 0.00 & 0.0 & 16.00 & \\
\hline 2 & Slurry & $10: 28$ & PrimeFRAC 15 & 1000 & 1.00 & 1.0 & 16.00 & CarboProp 20/40 \\
\hline 3 & Slurry & $13: 39$ & PrimeFRAC 15 & 2000 & 2.00 & 4.0 & 16.00 & CarboProp 20/40 \\
\hline 4 & Slurry & $21: 53$ & PrimeFRAC 15 & 5000 & 3.00 & 15.0 & 16.00 & CarboProp 20/40 \\
\hline 5 & Slurry & $37: 11$ & PrimeFRAC 15 & 9000 & 4.00 & 36.0 & 16.00 & CarboProp 20/40 \\
\hline 6 & Slurry & $59: 58$ & PrimeFRAC 15 & 13,000 & 5.00 & 65.0 & 16.00 & CarboProp 20/40 \\
\hline 7 & Slurry & $61: 47$ & PrimeFRAC 15 & 1000 & 6.00 & 6.0 & 16.00 & CarboProp 20/40 \\
\hline 8 & Flush & $72: 07$ & PrimeFRAC 15 & 6948 & 0.00 & 0.0 & 16.00 & \\
\hline Design clean volume (bbls) & & & 1046.4 & \multicolumn{4}{|c|}{ Design proppant pumped (klbs) } & 127.0 \\
\hline Design slurry volume (bbls) & & & 1154.1 & \multicolumn{4}{|c|}{ Wellbore Volume } & $6948 \mathrm{gal}(164.5 \mathrm{bbls})$ \\
\hline
\end{tabular}

Table 3 Hydraulic fracture growth history

\begin{tabular}{llllllll}
\hline $\begin{array}{l}\text { End of } \\
\text { stage \# }\end{array}$ & Stage type & Time (mm:ss) & $\begin{array}{l}\text { Fracture half- } \\
\text { length (ft) }\end{array}$ & $\begin{array}{l}\text { Fracture } \\
\text { height (ft) }\end{array}$ & $\begin{array}{l}\text { Fracture width } \\
\text { at well (in) }\end{array}$ & $\begin{array}{l}\text { Avg. fracture } \\
\text { width (in) }\end{array}$ & $\begin{array}{l}\text { Slurry efficiency } \\
1\end{array}$ \\
\hline 1 & Main frac pad & $8: 55$ & 207 & 90 & 0.306 & 0.196 & 0.59 \\
2 & Main frac slurry & $10: 28$ & 221 & 92 & 0.317 & 0.202 & 0.56 \\
3 & Main frac slurry & $13: 39$ & 253 & 98 & 0.361 & 0.225 & 0.59 \\
4 & Main frac slurry & $21: 53$ & 338 & 115 & 0.415 & 0.242 & 0.63 \\
5 & Main frac slurry & $37: 11$ & 455 & 138 & 0.498 & 0.270 & 0.66 \\
6 & Main frac slurry & $59: 58$ & 572 & 165 & 0.605 & 0.304 & 0.70 \\
7 & Main frac slurry & $61: 47$ & 579 & 167 & 0.613 & 0.307 & 0.70 \\
8 & Main frac flush & $72: 07$ & 617 & 177 & 0.655 & 0.321 & 0.71 \\
\hline
\end{tabular}

\section{SN Applied Sciences}


for the optimized fracturing treatment and the economic feasibility of the project. Although the materials (used in this study) can vary depending upon the reservoir condition, the criteria defined above are very much feasible for optimally designing any hydraulic fracturing treatment.

For designing a hydraulic fracturing treatment, a fracturing model is required for the fracture propagation in the formation. The 2D model works on assuming the height of the fracture and with this calculating the fracture half-length or width. It, however, does not incorporate the stress barriers and stress effects of the reservoir. In the actual scenario, the fracture geometry changes with these stress conditions. Therefore, using a 2D model can only predict a simplified fracture dimension, but realistically these dimensions tend to vary as the fracture propagates deep into the reservoir. The 3D shear decoupled model simulates an efficient fracture propagation, as it tends to include the stress conditions during the fracture propagation. Moreover, it models the fracture propagation in all three dimensions with the variation of fracture geometry based on the reservoir stress constraints.

From the selection of the materials, it is evident that the permeability, conductivity, and beta factor contribute significantly to the selection of the proppants. Higher permeability and conductivity provide effective hydrocarbon production, whereas the beta factor deals with the nondarcy pressure drop effects and quantifies the best suitability of material with the reservoir. It is to be noted that these parameters should be considered based on their sensitivity to the insitu stresses.

The fracturing fluid should be selected depending upon its viscosity and compatibility with the reservoir. The selection of the fluid varies with different properties of formations because the fluid behaves differently in different formation types. Dealing with this criticality requires the consideration of different fracturing fluid and additives. In this study, the PrimeFrac is used as a fracturing fluid because it is delivering an effective performance with regards to fracturing the formation. However, for different reservoirs, different fracturing fluid can be preferred depending upon the selection criteria described earlier. Apart from reservoir compatibility, the viscosity of the fluid must be maintained at optimum values to fracture the formation and carry the proppants into the reservoir.

For any reservoir, the Fcd values must be kept within the limit of 15 as it generally provides infinite conductive fracture, which is highly feasible for high gas production. Moreover, the fracture half-lengths must be increased in the reservoir while considering the Fcd values. Higher half-lengths give higher conductivities and optimum Fcd values. However, the fracture half-lengths should not be increased indefinitely as the fracture may collapse because of the insitu stresses. Moreover, the treatment size (or the amount of proppant pumped) increases considerably with very high fracture half-lengths. Hence, a reasonable fracture half-length should be chosen while considering treatment sizes, insitu stresses, and Fcd values. With this, a sensitivity should always be run on the production performance of the fractures to determine the most effective fracture half-length and hence the fracture design for a proposed hydraulic fracturing treatment.

\section{Conclusion}

In this study, an approach has been presented to design an optimum fracturing treatment in a tight gas reservoir. It covers the fundamental aspects of fracturing design which includes the fracture model selection, material selection, and fracture half-length selection for effective hydraulic fracture treatment and efficient production performance of the reservoir. This study will, therefore, help design future hydraulic fracturing treatment in an optimized manner. Based on this study, the following conclusions can be drawn:

1. The 2D fracture models restrict the fracture propagation in all three dimensions as the height of the fracture is assumed. Realistically, the fracture propagates with varying heights, widths, and lengths depending upon the stress conditions and stress barriers in the reservoir. Therefore, the 3D fracture propagation model is an effective tool to understand the fracture propagation in all three dimensions with stress variations.

2. The selection of proppant is highly dependent on stresses prevailing in the reservoir. Its permeability, conductivity, and beta factor vary with stress constraints. A proppant with higher permeability, higher conductivity, and lower beta factor provide higher recovery of hydrocarbon in the reservoir. Therefore, consideration should always be given to permeability, conductivity, and Beta factor under stress for selecting any proppant.

3. The reservoir pressure, reservoir temperature, and fluid viscosity extensively help in selecting an appropriate fracturing fluid. Based on this consideration, PrimeFRAC is found to be compatible with reservoir formation and fluid viscosity in this study.

4. While designing any fracture, the dimensionless fracture conductivity ( $F c d$ ) value should be kept within $10-15$, because after the Fcd value of 15 , the effective wellbore radius does not increase, hence no significant impact on production will be observed. 
5. It has been found through simulation that fracture conductivity directly increases with the fracture halflengths. It follows a linear trend.

6. Simulation results show that the fracture half-length has a direct relation with the productivity index (PI) ratio. Higher fracture half-lengths provide high values of productivity.

7. The treatment size (or amount of proppant pumped) increases with the increase in fracture half-lengths. However, it has certain restrictions. In this study, it is found that upto $800 \mathrm{ft}$ of fracture, the treatment size gets a minor increase in value. However, after $800 \mathrm{ft}$, a significant increase in treatment size is observed with the increase in fracture half-length. Hence, in general, there will always be a limit upto which a small increment in treatment size will be observed. After that limit, the treatment size tends to grow considerably.

8. The simulation shows that the production rates, cumulative production, and productivity index increases with fracture half-lengths. The higher the half-lenghs the higher the gas production.

9. Water saturations largely restricts the flow of gas in the reservoir. It is observed that the gas production decreases with the increase in reservoir water saturation.

10. The optimized hydraulic fracture is obtained at 618 $\mathrm{ft}$ fracture half-length as it provides high gas production from the reservoir. However, the fracture halflength greater than $618 \mathrm{ft}$ is not considered as optimized because higher lengths may collapse from the fracture tip due to formation stresses. Moreover, the proppants required is also high in the higher fracture half-lengths. Apart from this, the production has less difference as compared to $618 \mathrm{ft}$ fracture. Hence, in general, the moderate fracture half-lengths provide efficient performance in tight gas reservoirs.

\subsection{Future work}

This study does not include permeability heterogeneity in the reservoir. Therefore, the future work will be to import this fracture design into a reservoir simulator and determine its production performance while considering the permeability heterogeneity in the reservoir.

Acknowledgements We would like to acknowledge Mehran University of Engineering and Technology, SZAB Campus, Khairpur Mirs' Sindh, Pakistan and Mehran University of Engineering and Technology, Jamshoro Sindh, Pakistan for allowing us to publish this paper. We also acknowledge Carboceramics for their educational license of Fracpro Software.

\section{Compliance with ethical standards}

Conflict of interest On behalf of all authors, the corresponding author states that there is no conflict of interest.

\section{References}

1. Khan R, Al-nakhli AR (2012). An overview of emerging technologies and innovations for tight gas reservoir development. In: Paper presented at SPE International Production and Operations Conference \& Exhibition, 14-16 May, Doha, Qatar. SPE-155442-MS. https ://doi.org/10.2118/155442-MS.

2. Ostojic J, Rezaee R, Bahrami H (2012) Production performance of hydraulic fractures in tight gas sands, a numerical simulation approach. J Pet Sci Eng 88-89:75-81. https://doi.org/10.1016/j. petrol.2011.11.002

3. Md Yus of MA, Mahadzir NA (2015) Development of mathematical model for hydraulic fracturing design. J Pet Explor Prod Technol 5:269-276. https://doi.org/10.1007/s13202-014-0124-z

4. Tiab D, Donaldson EC (2016) Shale-Gas Reservoirs. In: Tiab D, Donaldson EC (eds) Petrophysics. Gulf Professional Publishing, Houston, pp 719-774. https://doi.org/10.1016/B978-0-12-80318 8-9.00012-7

5. Lashari N, Bashir S, Siraj F, Baloch M (2012) Production optimization of tight gas reservoir through hydraulic fracturing. Bachelor's thesis, Mehran University of Engineering and Technology, Jamshoro, Pakistan

6. Adachi J, Siebrits E, Peirce A, Desroches J (2007) Computer simulation of hydraulic fractures. Int J Rock Mech Min Sci 44(5):739-757. https://doi.org/10.1016/j.ijrmms.2006.11.006

7. Wong JK (2018) Three-dimensional multi-scale hydraulic fracturing simulation in heterogeneous material using Dual Lattice Model. Doctoral thesis. https://doi.org/10.17863/CAM.17439

8. Guo B, Lyons WC, Ghalambor A (2007) Hydraulic fracturing. In: Guo B, Lyons WC, Ghalambor A (eds) Petroleum production engineering: a computer assisted approach. Gulf Professional Publishing, Houston, pp 251-265. https://doi.org/10.1016/B978-075068270-1/50023-2

9. Allen TO, Roberts AP (1994) Production operations. OGCl and PetroSkills Publications, Tulsa

10. Geertsma J, Haafkens R (1979) Comparison of the theories for predicting width and extent of vertical hydraulically induced fractures. J Energy Resource Technol 101(1):8-19. https://doi. org/10.1115/1.3446866

11. Wright CA, Weijers L, Davis EJ, Mayerhofer M (1999) Understanding hydraulic fracture growth: tricky but not hopeless. In: Paper presented at SPE annual technical conference and exhibition, 3-6 October, Houston, Texas. SPE-56724-MS. https://doi. org/10.2118/56724-MS.

12. Abaa K, Wang JY, Ityokumbul MT (2013) Parametric study of fracture treatment parameters for ultra-tight gas reservoirs. J Pet Explor Prod Technol 3:159. https://doi.org/10.1007/s13202-013-0058-x

13. Economides MJ, Nolte KG (2000) Reservoir stimulation, 3rd edn. Wiley, New York

14. Economides MJ, Hill AD, Ehlig-Economides C (1994) Petroleum production systems. Prentice Hall, Englewood Cliffs

15. Cinco-Ley H, Samaniego VF (1981) Transient pressure analysis for fractured wells. J Pet Technol. https://doi.org/10.2118/7490-PA

16. Al-Sadhan N (2014) Prediction of short-term and long-term baseline conductivity degradation for proppants of different types and sizes. Doctoral thesis. https://hdl.handle.net/11124/17006

Publisher's Note Springer Nature remains neutral with regard to jurisdictional claims in published maps and institutional affiliations. 